\title{
A Closer Look at Information Systems Graduate Preparation and Job Needs: Implications for Higher Education Curriculum Enhancements
}

\author{
DeShea Simon ${ }^{1, *} \&$ Kanata Jackson ${ }^{2}$ \\ ${ }^{1}$ Computer Science Department, Hampton University, 100 E. Queen St. USA \\ ${ }^{2}$ School of Business, Hampton University, 100 E. Queen St. Hampton Virginia, USA \\ *Corresponding author: Computer Science Department, Hampton University, 100 E. Queen St., Hampton VA 23668, \\ USA. Tel: 1-757-282-5732 E-mail: deshea.simon@hamptonu.edu
}

\author{
Received: March 23, $2013 \quad$ Accepted: May 3, $2013 \quad$ Online Published: June 5, 2013 \\ doi:10.5430/wje.v3n3p52 URL: http://dx.doi.org/10.5430/wje.v3n3p52
}

\begin{abstract}
A historical review of the literature surrounding IS skill requirements was conducted for this study to provide the changes in IS over the past several decades. Providing a historical look at the literature will place into perspective the fact that the field changes rapidly, causing the need for the IS professional to also continuously change. The results of the investigation revealed that a consensus exists regarding the perceptions of the skills needed for the IS worker.
\end{abstract}

Keywords: information systems; job needs; graduate programs; job skills; job readiness

\section{Introduction}

Industry is placing more emphasis on recruiting individuals with an understanding of technology and information systems (IS) (Brandel, 2010). The goal of recruitment is to find high-quality individuals appropriate for an organization at the lowest cost possible. However, companies sometimes find that new recruits do not perform as expected. This issue can be found in some IS departments where a mix of skills are required. When new recruits do not perform as expected, frequent turnover and instability in the department can occur. A lack of quality enterprise-wide IS development, integration, and maintenance may also result. Therefore, the professional knowledge and skills of IS employees is a significant part of an organization's ability to maintain strategic and financial competitiveness (Tarafdar \& Gordon, 2007).

Universities are responsible for graduating IS students with the skills necessary to succeed in a rapidly changing technological environment. Because high-quality employees enhance the quality and performance of enterprise-wide IS within an organization, communicating and understanding the skills required for IS work is important. Therefore, the need for graduates with current skill requirements is of constant concern. For the past 20 years, various articles have been written about the skill expectations needed by such technical professionals as IS workers and the satisfaction of the industry from a qualitative and quantitative perspective (Trauth, Farwell, \& Lee, 1993; Ashley \& Padget, 1998; Kim, Hsu, \& Stern, 2006). Understanding the skills needed of IS workers is imperative because as the economy changes, industry requirements also change, causing a need for skill requirements to be reassessed periodically.

According to Trauth et al. (1993), academic programs in IS have been questioned for graduating individuals lacking the necessary skills to perform IS work, and educators have admitted that they "are concerned about not being able to mimic business environments in a classroom setting to teach required skills" (p. 294). Ashley and Padget (1998) stated that "undergraduate programs have been trying to meet the skill requirements to produce qualified IS professionals, but they are not keeping up" (p. 4). Since satisfying the staffing needs of the marketplace is a major focus for employers, IS hiring managers seek individuals who already possess practical experience and current IS skills (Kim et al., 2006). Organizations look to universities to provide such individuals; therefore, it is important to explore if individuals who intend to work in this discipline are adequately prepared by the academic institutions they attend. 


\section{Literature Review}

\subsection{Historical Beginnings}

The field of IS, as it relates to the computerized systems used today, began in the 1960s (Halawi \& McCarthy, 2006). As organizations began to incorporate information processing and technical communications into daily operations, the breadth of the field grew exponentially. IS as a field of study includes the concepts, principles, and processes for two areas of activity within organizations. The first area consists of acquisition, development, and management of technical resources and services. The second is the development, operation, and evaluation of infrastructure and systems for use in organizational processes (Gorgone et al., 2002). Professionals in the IS field design, use, and support information technology to achieve organizational goals. Initially, the discipline was associated with the following terms: information management, information resource management, management of information systems, and computer information systems. Over time, the discipline has expanded to include information technology (IT). This subset of information systems is the use of hardware and software to manage IS; in many organizations, this is referred to as management information systems (MIS) or information systems. According to Lenox and Woratschek (2003), "All information systems have information technology as a core ingredient" (p. 6).

In the early 1970s, few studies were published on IS skills; however, by 1976, researchers had identified managerial and interpersonal skills as the most important skills needed for the IS profession (Todd, McKeen, \& Gallupe, 1995). In 1980, the work of Cheney and Lyons revealed that there was uncertainty about the types of skills necessary for IS professionals. Therefore, they conducted a study that examined employment trends in IS. Their work showed that IS managers perceived technical knowledge and management skills as the most important skills to possess. According to the researchers, such skills were closely associated with job performance (Cheney \& Lyons, 1980). By 1981, organizations such as the Association for Information Systems (AIS), Association for Information Technology Professionals (AITP), and Association for Computing Machinery (ACM) helped to define IS as a distinct area of computing (Lenox \& Woratschek, 2003). Collectively, these associations have designed curriculum models for IS undergraduates. The goal of these models is to serve as a guide a sufficient mix of skills necessary for IS professionals to be competent in the field.

\subsection{IS skills Revisited for Industry Needs}

However, in 1993, Trauth et al. revisited the IS skill requisite issue by conducting a multiphase study. The study revealed that a combination of technical, human, and business skills are needed for employable IS professionals. The study also revealed that there were observable differences in the expectations of skill requirements by industry and what academia understands the expectations of industry to be. Such differences have created a gap, preventing the development of skilled, employable IS professionals. These researchers identified this disconnect as "The IS Expectation Gap" (Trauth et al., 1993, p. 294). Coverdale and Zaveri (2003) explained this gap further, stating that "Information Systems practitioners have frequently criticized the professional readiness of graduates emerging from information systems academia, and information systems educators have complained of inadequate input from practitioners on what to include in program offerings" (p. 423). This type of miscommunication can negatively impact the skill development of individuals pursuing a degree to become prepared IS processionals, causing a lack of sufficient skill development in information systems workers.

To address what constitutes a prepared IS professional; Noll and Wilkins (2002) studied the requirements of industry over a 3-year time frame. The results of the survey supported the research previously conducted by Trauth et al. in 1993. From their data, Noll and Wilkins (2002) concluded that "programs can be developed to target the diverse IS job market" (p. 152) and they agreed that a mixture of human, technical, and business skills are the major skill requirements that should be developed when creating well-educated and prepared skilled IS professionals for the job market. A lack of the required skills could lead to errors in data collection, hardware configuration, software development, and procedures. These inaccuracies cost a company time and money, impacting organizational growth and success.

Within the last 7 years there has been a decline in the attention paid to this phenomenon of job ready skills. Researchers Kim, et al. (2006) published an update on the IS skills gap which showed that project management skills, though vital are most often absent from IS programs. Proficiency in project management is ranked number one among the technical skills needed in organizations ("IT Staffing Report," 2005). In 2008, Gallagher, Kaiser, Simon, Beath, \& Goles designed six categories for skill development based on data drawn from multiple years of research in the subject area. From their research various skills were identified further supporting the need for todays IS professional to possess both technical and non-technical skills. More recent publications also discuss the skills that are needed by information systems professionals but are lacking (“Forbes,"2012, "Computer World," 2012). 
Although there is expected growth in information systems positions, there is still universal concern about the enrollments in information systems programs which compounds the importance of the need for skilled graduates in this field. To address this issue, many universities encourage internships as a means of developing skills not obtained in the classroom; others have implemented a modular approach (Braun, Crable, and Sena, 2008) to teaching courses, while others have introduced Higher Order Thinking (Wang, Shouhong, and Wang, 2011) and even rational participation (Haihe, 2011).

\subsection{Program Graduates Assessment of Job Readiness}

Although skill requirements in the IS discipline have been researched, the focus of this study was to explore the perspectives of IS graduates on their preparedness for the IS job market. This information is useful because it can assist in the preparation of individuals for the IS profession. Because academia is constantly trying to map, revise, update, and adjust skill development techniques, a deeper understanding of how to acquire current skills would help to improve the employee recruitment process. Studying IS skill trends is important as it can impact the mix of skills sought, the skills retained, and the skills outsourced. Organizations increasingly depend on IS as they experience more global competition, volatile marketplaces, and reduced product life cycles. IS solutions must be constructed and implemented rapidly and efficiently despite the constant changes in technology. Exploring ways to effectively understand skills needed in the discipline will help organizations to stay abreast of system analysis, design, and rapid application development (RAD) that are vital to the success of IS deployment. Adopting an information system can be a significant task for managers; therefore, a substantial amount of thought must go into employing individuals with the necessary skills to develop and sustain this technology. A better understanding of the skills needed in the IS work force can lead to a better match between employers and IS workers.

This research study used a nonexperimental, qualitative research design to allow a descriptive interpretation of the views of recent IS graduates. An interview guide (see appendix) was used to facilitate the collection of qualitative data of the participants. The interview guide was divided into 4 distinct areas in order to collect information about program elements, job preparation, skill development and the state of information systems in university programs. The data collected was analyzed and summarized manually using reputable word processing and data analysis software. No incentives were offered for participation, and anonymity of the participants was maintained throughout the study.

\subsection{Industry Information Systems Skill Requirements}

A historical review of literature surrounding IS skill requirements was conducted for this study to provide the changes in IS over the past several decades. Providing a historical look at the literature will place into perspective the fact that the field changes rapidly, causing the need for the IS professional to also continuously change. This review also highlights the need for comprehensive preparation for IS professionals. Therefore, the literature review addresses various skills throughout history that contributed to the development of a prepared IS professional for the 21 st century.

Skill sets needed by IS professionals have been a subject of study from both academic and industry perspectives (Outlay \& Krishnan, 2010). These skill sets include basic, advanced and mastery levels. One of the first experimental studies in this area can be found in the research of Shrout (1970). Four hundred sixty-eight system analyst professionals were surveyed on 98 competencies in this research. The nature of jobs performed by IS analysts and the importance of competencies needed for these jobs were the focus of the study. A questionnaire was mailed to a sample of systems analysts drawn from the Association for Systems National Management that asked the participants to indicate the "degree of importance" (Shrout, 1970, p. 79) for each competency and its importance 5 years into the future. The data collected were coded to classify the responses on a scale from very important to unimportant. The results revealed that the skills considered to be most important were communicating clearly and working with all levels of the organization (Shrout, 1970). This suggests that communication and teamwork are necessary for IS work.

\subsection{Communication Skills Identified as Integral to Employee Success}

Communication involves the use of messages to generate meaning across various contexts (Association for Communication Administration, 1995). Communication, such as presentations, in organizations is highly valued by employers (Baugh, Davis, Kovacs, Scarpino, \& Wood, 2009). IS professionals must perform these types of communications with various groups on a regular basis to use and develop IS successfully. Communication requires a sender, a recipient, and a transfer of meaningful information. The communication process is complete once the recipient understands the information conveyed by the sender. Communication can be conveyed in two forms: verbal and written. Verbal communication implies spoken words as a means to communicate. Written communication 
typically relies on text, visual aids, and nonverbal elements to convey meaning.

In the IS discipline, frequent communication is needed to obtain requirements, determine expectations, and ensure the success of the final system under development. Colleges and universities have recognized the importance of communication skills, both oral and written, by incorporating components into their programs (Bakke, 2008; Becker, 2008; Giangrande, 2009). However, organizations continue to struggle with recent college graduates who lack communication skills (McPherson \& Mensch, 2008).

\subsection{Teamwork is Key}

Working with all levels of the organization suggests teamwork. Teamwork is necessary in IS development because systems development is critical to the success of organizational productivity. IS professionals must be able to work well in teams to design and modify systems that improve production, work flow, or additional systems development. Teamwork has become an essential part of the working philosophy. As stated earlier, when evaluating a person for employment, businesses now require the ability to work in a team. As products become more complex to manufacture, the ability to work in teams prior to entering the work force will become more crucial. Typically, teamwork is incorporated into an IS course through the use of group projects (Wehrs, 2002). However, simply completing a project with a fellow classmate does not ensure that students have learned to effectively work as a team (Cohen, 2002).

The Myers-Briggs Type Indicator (MBTI) is a tool often used by businesses to achieve the goals of building work teams (Capretz \& Ahmed, 2010). Published in 1944 by Isabel Myers-Briggs, the MBTI is a personality test designed to identify personal preferences of individuals. The MBTI includes 93 questions and employs psychometric techniques to score and identify which dichotomy individuals prefer. Using a tool such as the MBTI can assist in constructing a team in which people are assigned to different aspects of a project that best suit their ability. Employing this instrument is valuable in designing teams in the IS discipline and should be integrated into programs to develop future IS professionals in this area (Drexel \& Roberson, 2010).

Systems development often involves teamwork as various people work together to perform numerous tasks. This suggests that the human factor is one of vital importance in professions that require teamwork. Therefore, it is important that graduates learn how to function in a team environment. Companies realize that teamwork is important to produce better products and services in a timely fashion. However, according to Figl (2010), "although team competencies have been integrated into university programs, existing programs still lack substantial effort to include the promotion of team competencies" (p. 2).

Cheney and Lyons (1980) conducted a study to examine the changes in skill requirements in the work force. Thirty-two IS managers from large national organizations were asked to participate in the study. The participants were surveyed on their opinions of the importance of skills for IS personnel. The participants were asked to rank these skills for three groups: managers, systems analysts, and programmers. The results revealed that the most important skills needed by IS employees were an understanding of computers and IS concepts. An understanding of such technical concepts suggests that cognitive ability is vital in the IS profession. IS professionals must be able to understand how technology and system development can be utilized to enhance organizational objectives and performance. Although managers found cognitive ability to be important, systems analysts and programmers, found communication and teamwork to be most important, which was consistent with the research of Shrout (1970). This finding suggests that management may be removed from the hands-on operations needed to perform work in the field.

During the same year, Benbasat, Dexter, and Mantha (1980) conducted a survey that also examined which IS skills were perceived as beneficial to organizations. The study sought to test multiple hypotheses related to IS skills needed by IS professionals; the Nolan stage model was used to create 11 criteria for a questionnaire to classify IS skills for IS professionals. The respondents were asked to indicate the perceived usefulness of each skill using a scale from 1 to 5. The survey was mailed to various organizations and IS managers and systems analysts were asked to fill out the questionnaire. The results indicated that managers and analysts alike found that general skills versus specialized skills were more useful. This finding indicated that "systems analysts were oriented toward problem solving rather than technical problems" (Benbasat et al., 1980, p. 30). This suggests that cognitive and interpersonal abilities are essential to successfully perform the duties of an IS professional. Interpersonal skills, also referred to as soft skills or people skills are essential when interacting with other members of an organization. Interpersonal skills can include listening, problem solving, communication, attitude, and behavior. IS professionals with good interpersonal skills are likely to form partnerships and establish relationships that will allow them to solve problems and carry out timely service requests. 
An understanding of the role computers play in business operations can help companies sustain a competitive advantage. It has become increasingly important that IS workers have an understanding of organizational goals, objectives, and technical requirements. Therefore, IS graduates must also understand how information systems meet the goals and objectives of an organization. Maintaining current technical knowledge of system requirements, design, and security is extremely important. While demand for competent IS professionals is on the rise, it has been acknowledged that individuals entering this profession often lack the ability to elicit and understand requirements (Pitts \& Browne, 2004; Chakraborty \& Sarker, 2007).

McCubbrey and Scudder (1988) investigated the type of skills that would be needed by the systems analyst of the 1990s. Their study was based on the table of IS skills identified by Nunamaker, Cougar, and Davis (1982). IS practitioners were asked to comment on whether IS skills had become more important, less important, or remained the same. They were also asked to provide additional skills to include as part of the instrument. The skills were grouped into the following categories: people skills, modeling skills, systems skills, computer skills, organizational skills, and societal skills. The survey results indicated that people in IS will need to perform at a more theoretical level. These individuals will work together with management to define functionality for IS and, according to the researchers, IS professionals will "no longer be concerned with defining the blueprint for the systems as they will be with the definition of what the systems will do" (McCubrey \& Scudder, 1988, p. 13). As with Cheney and Lyons (1980) and Benbasat et al. (1980), the findings suggested that IS practitioners need to be able to understand system functionality and present it in various theoretical models. A concern with how the systems will operate implies that the IS professional will do more than just design or code to ensure the success of the system. Therefore, performing at a more interpersonal level will be needed to obtain an understanding of the operations within the organization.

Watson, Young, Miranda, Robichaux, and Seerly (1990) conducted a study to investigate the type of skills that were needed by IS professionals during the 1990s. IS managers and other IS professionals were surveyed to design a list of skills required for the following IS personnel: programmers, systems analysts, and end users. The researchers asked members of the University of Georgia MIS advisory board to hold an open discussion on selected skills. Based on this discussion and previous literature, 16 skills were selected and included in the study. Four additional skills were added to the list using the PLEXSYS analysis tool. These skills were entered into a voting module and each participant was asked to rank the skills. Results from the module revealed that while programming is fundamental for personnel choosing to specialize in IS, systems analysis and design and the ability to solve problems were extremely important for IS work. These findings supported those of McCubbrey and Scudder (1988), suggesting that interpersonal and problem-solving skills will play a key role in the performance of IS professionals.

\subsection{IS Skills are Needed for Problem Solving}

Problem solving, also referred to as analytical thinking, is the process of identifying and working through the specifics of an issue to reach a viable solution. This process is referred to as the problem-solving cycle. The cycle consists of the following seven stages: (a) identify the problem, (b) define the problem, (c) gather information about the problem, (d) decide the best solution, (e) allocate resources to solve the problem, (f) take action, and (g) evaluate the outcome. Problem solving is an important component of most professions and has been viewed as an important nontechnical skill in IS development (Drohan, Stapleton, \& Stack, 2006). Through the use of problem solving, one can draw reasonable conclusions to produce viable outcomes. IS professionals must be able to draw meaningful conclusions from information to understand problems within the organization and identify information that can be used to propose possible resolutions and develop strategies to solve problems and communicate the answers. Although universities have developed various courses to introduce problem solving, "IS practitioners believe that higher educational institutions are failing to supply graduate recruits with an adequate level of problem solving skills required by industry" (Drohan et al., 2006, p. 1).

Analytical thinking is a methodical process to break down complicated problems. In IS requirements, analysis is critical to the success of IS development. Understanding user requirements is an essential part of IS design. Requirements analysis is useful for requirements elicitation and can help to identify issues that need to be solved. Analytical skills enable IS professionals to understand an organization and its operations, recognize opportunities, and identify the potential limitations of IT. Analytical thinking is critical and logical. Analytical thinkers assess ideas and determine the most reasonable outcomes to form a logical thought. Through the use of analytical thinking, individuals are able to solve effectively social, scientific, and practical problems (Shakirova, 2007). Analytical thinkers raise questions and gather information to deliberate and form reasonable conclusions. Many colleges and universities offer courses designed to increase critical thinking skills. However, analytical thinking has been reported as one of the top four skill gaps in recent gradutes (Stevens-Huffman, 2011). 
Leitheiser (1992) examined the demand for IS jobs and the importance of IS skills to also provide a perspective on current demand of skills in IS professionals. The researcher developed an instrument based on previous empirical research that included the work of Cheney and Lyons. The instrument was designed to capture information on various jobs in the IS field and the changes in these positions, rate skills by importance, and rank specialist skills by importance. Skills were also taken from the documentation of Nunamaker and included in the study. The results indicated that interpersonal skills were rated highest. Leitheiser (1992) recognized that "although this is not a new result it's one that needs to be re-emphasized" (p. 86). This suggests that the revitalization of interpersonal skills development will continue to become more important for IS professionals. Thus far, interpersonal skills have been previously identified by Shrout (1970), Cheney and Lyons (1980), McCubbrey and Scudder (1988), and Watson et al. (1990) as important for IS professionals to possess, and Leitheiser (1992) recommended that an emphasis should be placed on interpersonal skills as the IS field moved forward in the 20th century.

Trauth, Lee, and Farwell (1995) conducted a study in response to the concerns of the changing skill needs of information systems and their impact on the IS professional. The research consisted of discussion forums and questionnaires completed by members of the Society for Information Management. The goal of the forums was to obtain views about information skill requirements from various business managers, and the survey asked participants to rank the various skills, which were once again taken from the table of IS skills by Nunamaker.

According to the researchers, the results suggested that IS professionals with business knowledge, technical ability, management, and interpersonal skills will be needed to effectively perform the IS operations required by industry (Trauth et al., 1995). These findings do not drastically differ from the findings in the literature previously discussed.

However, management is a newly mentioned skill, which implies that direct communication between IS professionals and other employees within the organization will be necessary. Therefore, IS professionals must be competent communicators (Shrout, 1970).

Todd et al. (1995) examined job advertisements from 1970 to 1990 to determine the correlation between changes in IS skill requirements and the skills requested in job announcements. Job ads from U.S. newspapers were examined by the researchers specifically for IS job skills. The research was comprised of 348 ads for systems analysts and 305 IS management positions. Between 1970 and 1990, there was a 40\% increase in a need for technical skills for system analyst positions (Todd et al., 1995). However, the researchers noted that by 1990, the frequency of technical skills was just beginning to match the frequency of business and system process skill requirements. These increases suggest that skills in development of hardware and software became increasingly important in the IS profession over time. However, business and system process skills have been in great demand continuously. The researchers identified the primary business skills and system process skills to be communication and problem solving. This suggests that skills such as these have been requested by industry but may be lacking in curriculum designed to develop such skills in those who wish to enter the IS profession.

In 1996, Misic conducted a survey of systems analysts to assess the skills needed for IS positions and determine if IS environments had an impact on skill requirements. The survey was sent to 276 organizations from a directory of top computer executives. Participants were asked to rank 35 system analyst tasks by order of importance. Each task was rated from 1 to 5 . The results of the study showed that IS positions require individuals with an analytical skill set versus a strong technical skill set; environment had no effect on the skill requirements for the position. Based on the results, Misic (1996) recommended that "information systems professionals with solid analytical skills, supported by technical and communication skills should be able to work successfully in a constantly changing systems development environment" (p. 8), which supported the findings of Todd et al. (1995). Jacobson and Armstrong (2000) analyzed job advertisements to determine which IS skills were in demand by business and government organizations and to identify skill changes from their initial 1998 study. As with industry, governments utilize IS to perform local and global transactions and protect against tampering of data, fraud, unauthorized disclosure of sensitive information, and disruption of critical operations. One thousand seventy-three ads were collected from four newspapers and tallied for analysis. The skills were classified into the following categories: general job skills, IS skills, software knowledge, hardware knowledge, and telecommunications knowledge.

The findings revealed that software knowledge was found most throughout the solicitations included in the research. This suggests that there is a technical emphasis on the desired skills for IS workers, which is a contradiction to the findings of Todd et al. (1995). A reason for this discrepancy may be that Todd et al. collected ads from across the United States and Canada, whereas Jacobson and Armstrong (2000) collected ads solely from the Mid-Atlantic region. However, various technical activities fall within the realm of IS within an organization. The shift into an information economy requires a high level of technical skills in IS to perform tasks such as managing network 
security and directing Internet operations. Therefore, IS professionals are often expected to be qualified in different technical areas, including areas such as database development, system design and integration, technical support, web development, and programming.

Hardin, Joshi, and Li (2002) examined IS requirements since the emergence of the Internet era. Their study expanded on a previous study conducted by Todd et al.. Data from the U.S. Department of Labor and Internet ads from 1997 and 2001 were included in the research. The statistical data were tallied for technical positions, which included systems analysts and are managers. The year 1997 contained a higher demand for IS jobs in 2001; therefore, 100 job ads were examined and compared to ads from 2001. The data collected were analyzed using the same measurements used in the study by Todd et al. The measures assessed knowledge skills and abilities for nontechnical skills. According to the results of the study, technical skills were identified as the most required skills for the Intertent era. These results also fall in line with Jacobson and Armstrong (2000) identifying technical skills as most substantial and skills such as communication and problem solving as less important.

However, Kittner and Papp (2004) conducted a study to determine IS skills in demand by employers. The researchers conducted their study to better understand the changing demand for IS professionals and provide curriculum suggestions for IS educators. The study also analyzed classified ads for IS jobs found in newspapers and on the Internet using major U.S. cities as the target population for the research. The coding methodology used in the study was modeled after Jacobson and Armstrong's. Advertisements for IS positions placed by consulting firms were used in the study. Using the coding scheme from the earlier research, information skills were identified and tallied. Results indicated that employers continued to seek project management ability, strong communication skills, and problem-solving skills, lending support to the study from Todd et al. (1995) that less technical skill are of greater importance.

\subsection{Project Management Skills Highlight IS Importance in Organizational Management}

A new skill identified in the study was project management. Project managers must communicate with team members to integrate and maximize performance throughout the different phases of a project. These individuals must be organized in order to keep track of meetings and pertinent documentation. Budgeting skills are necessary to perform cost estimates and problem-solving skills are necessary to define, analyze, and provide adequate solutions. Project managers should also have technical skills in areas such as computer languages, software, and networks. Managing development projects differs from traditional management because cross-functional collaboration, governance, and alignment of organizational elements and procedures are taken into consideration when conducting the project development cycle. This suggests that there is a distinct need for project management. However, companies continue to state that their employees lack project management skills (Anderson, 2012).

In 2005, the CIO Executive Council examined IS staffing needs and provided recommendations for the future. The council surveyed 303 IT executives for the study. The participants were asked to rate the following skills: leadership, problem solving, business knowledge, project management, and corporate strategy. According to the results, $70 \%$ of the senior IT executives stated that they needed a balance of business and technical skills in their employees; only $26 \%$ considered technical skills more important. Three-year projections also indicated that only $16 \%$ consider technical skills as most important. Furthermore, 99\% of the participants listed communication as most important, which suggests that business skills are becoming increasingly more important to employers.

In 2006, Kim et al. provided an update on the skill gap in IS. IS practitioners were asked to answer questions relating to the importance of courses in the IS 2002 model curriculum. Eleven courses were a part of the survey. The questionnaire was e-mailed to participants in manufacturing companies from the Northeast. The respondents were instructed to rate the importance of each course. Personal Productivity with Information Systems Technology, Introduction to Information Systems, and Project Management were found to be the three most important courses. The IS course introduces IS and demonstrates how these systems are integrated throughout global organizations. The Personal Productivity with Information Systems Technology course demonstrates the importance of relating IS goals to the goals of the organization. The Project Management course demonstrates how to manage business applications with time constraints and budget requirements.

Eight years later, the ACM revised the IS curriculum model and the Personal Productivity with Information Systems Technology course was removed. The course was removed because of the need for skills in globally distributed IS structures, the management and development of online platforms, new service-oriented architectures, enterprise systems that run on these platforms, and governance of organizational frameworks (Gorgone et al., 2002). Huang, Joshi, Kvasny, Mahar, and Trauth (2009) examined job skills within various forms of texts. The researchers used the ProQuest database to collect 116 scholarly articles. Using the keywords information technology and skills, 146 
practitioner articles were collected from technical journals. Two hundred forty-one online job ads were also collected using the Monster.com website. The job skills identified from each type of literature were categorized as follows: technical, business, or humanistic.

Analytical skills were listed as the most frequent technical skill within the scholarly literature, business knowledge was most frequent for the business category, and teamwork skills were most frequent in the humanistic category. Security was the most frequent technical skill found in the practitioner literature. Standard query language (SQL) was listed as the most frequent technical skill in the online literature, teamwork was most frequent in the business category, and communication was the most frequent humanistic skill. The researchers recognized that the research produced differences between the types of sources. While scholarly and practitioner literature classified teamwork as a humanistic skill, the online literature classified this skill as a business skill. Such discrepancies suggest that there is still a need to understand the basis for skill requisites of IS professionals and how to effectively communicate those skills between stakeholders such as scholars and practitioners. This also suggests that there is a need to continuously examine the changes in skill requirements over time. By re-examining skills periodically, stakeholders will be able to identify the changes in the needs for skills as technology changes in the organizational environment.

From the literature, there was great emphasis on the following IS skill requirements: communication, cognition, problem solving, analysis, teamwork, and project management, which suggests that employers are looking for dynamic IS graduates to fill positions within organizations. Employers are no longer looking for just strong technical skills; they are also looking for strong soft skills (U.S. Department of Labor, 2006).IS managers need IS employees with a keen understanding of people and processes. IS professionals must possess interpersonal skills because interaction is required with internal staff and external clients. Surendra and Denton (2009) contended that employers value interpersonal skills most and suggested that organizations place more emphasis on these skills. For this reason, soft skills are becoming a requirement of employers in addition to standard qualifications. Therefore, it is not sufficient for IS graduates to be solely technically competent, as social competencies, such as teamwork and communication, are also essential (Figl, 2010).

Although there was some consensus on the skills needed for IS professionals to be effective, Zaffar and Winter (2008) contended that the gap identified 15 years ago by Trauth et al. (1993) continues to be an issue. IS organizations play a major role in setting the skill expectations. Therefore, it is crucial that IS departments in organizations clearly articulate their requirements to academic institutions. It is also important that skill requirements are assessed on a continuous basis by both entities. Job advertisements appear to suggest that companies need IS graduates with the latest technical skills. This gives the impression that only technical skills are valued rather than the full range of skills that companies require. Difficulty in communicating the need for technical as well as communication, cognitive, problem-solving, analytical, teamwork, and project management skills presents a disadvantage to both employers and IS graduates looking for employment.

Despite the recent downturn in the economy, the demand for information systems workers remains strong. To remain competitive, firms in industry will continue to employ more complex networks and sophisticated Internet and intranet sites. Maintaining and integrating systems over networks is essential to organizations; therefore, companies will be more willing to hire skilled IS workers who can accomplish tasks related to these objectives. Due to the evolution of Internet commerce technology and the ability of the Internet to create relationships with customers worldwide, IS workers will continue to become more vital to companies. Therefore, academic institutions should continue to develop their programs to provide students with the knowledge and skills necessary to effectively prepare them for the workplace. Undoubtedly, sufficient technical skills are vital in the IS industry. Strong technical knowledge is essential for IS development and systems processes. However, IS professionals must also be able to understand business operations and communicate technical work in nontechnical terms to management and potential customers. Graduates possessing such skills must be competent and demonstrate appropriate practices in the workplace. Therefore, IS hiring managers must be able to effectively communicate their needs to academia to sufficiently staff their department.

\section{Discussion}

The 21st-century IS professional must blend technical and interpersonal skills to effectively understand and communicate business operations and organization strategies. Therefore, skill requirements must be understood within the organization and clearly communicated between recruiters, job applicants, and academia. While academia is addressing most of the technical skills through course content, nontechnical skills appear to require development beyond the traditional classroom environment. This implies that institutions should examine their current programs 
to ensure that the skills current IS professionals are using are aligned with what is being developed through university programs. In 2010, Employment Relations Today published an article suggesting that there is a need for collaboration between industry and education to facilitate the preparation of IS professionals (LaFrance, 2010). Such communication can help to ease the burden placed on educators to constantly stay abreast of an ever changing discipline.

The demand for IS skills has experienced resurgence over the past few years. Forecasts for positions with IS skill sets are currently strong, and job roles of IS workers are expected to continue to grow in the future. Since information technologies are being employed in new and creative ways, skill requirements have changed to being a mixture of technical and people centered, requiring IS workers to take on the roles of analysts versus programmers. Therefore, these analysts must possess skills to identify user and consumer needs and interpret these requirements into technology solutions. Various positions in IS work contribute to providing technical solutions for customer satisfaction; this means majors must research options available to them to make an informed decision on their career path within the discipline. Therefore, academic institutions should be aware of the various areas for career development in IS and design programs that provide skill development in these areas within the field.

\section{References}

Anderson, D. (2012). Can you do more with project management? Retrieved from http://technet.microsoft.com/en-us/gg634723.aspx

Ashley, N., \& Padget, T. (1998). Information systems graduates' evaluation of their curricula. Retrieved from http://www.westga.edu/ bquest/1998/infosys.html

Bakke, S. (2008). Try this sure-fire way to get students involved. Retrieved from proc.isecon.org/2008/3332/ISECON.2008.Bakke.pdf

Baugh, J., Davis, G., Kovacs, P., Scarpino, J., \& Wood, D. (2009). Employers and educators want information systems graduates to be able to communicate. Retrieved from www.iacis.org/iis/2009_iis/pdf/P2009_1209.pdf

Becker, K. (2008). The use of unfamiliar words: Writing and CS education. Journal of Computing Sciences in Colleges, 24(2), 13-19.

Benbasat, I., Dexter, A., \& Mantha, R. (1980). Impact of organizational maturity on information system skill needs. MIS Quarterly, 4(1), 21-34.

Brandel M. (2010). 6 hottest IT skills for 2010. Computer World. Retrieved from http://www.computerworld.com/s/article/345529/6_hottest_IT_skills_for_2010

Braun, G. F., Crable, E. A., \& Sena, M. P. (2010). A Modular Approach to Delivering an Introductory MIS Course. Information systems education journal, 8(36), 1-2. Retrieved from http://www.isedj.org/8/36/ISEDJ.8(36).Braun.pdf

Capretz, L., \& Ahmed, F. (2010). Making sense of software development and personality types. IEEE IT Professional, 12(1), 6-13.

Cheney, P. H., \& Lyons, N. (1980). Information systems skill requirements: A survey. MIS Quarterly, 4(1), 35-43.

Cohen, E. (Ed.). (2002). Challenges of information technology education in the 21st century. Hershey, PA: Idea Group.

Computerworld. (2012). 6 key skills the IT grads are lacking. Retrieved from http://www.computerworld.com/s/article/9224133/6_Key_Skills_IT_Grads_Lack

Creswell, J. (2003). Research design: Qualitative, quantitative, and mixed methods approaches (2nd ed.). Thousand Oaks, CA: Sage.

Drexel, P., \& Roberson, C. (2010). Using MBTI in a project-based systems analysis and design course. Retrieved from http://www.iiis.org/CDs2010/CD2010IMC/ICEME_2010/.../FB107FC.pdf

Drohan, S., Stapleton, L., \& Stack, A. (2006). Problem solving skills in information systems development curricula. Retrieved from www.aishe.org/events/2005-2006/conf2006/proceedings/paper-02.doc

Forbes. (2010). The IT skills gap. Retrieved from http://www.forbes.com/sites/ciocentral/2012/01/02/the-it-skills-gap/ 
Giangrande, E. (2009). Communication skills in the CS curriculum. Journal of Computing Sciences in Colleges, 24(4), 74-79.

Gorgone, J., Davis, G., Valacich, J., Topi, H., Feinstein, D., \& Longenecker, H. (2002). IS 2002 model curriculum and guidelines for undergraduate degree programs in information systems. Retrieved from http://www.acm.org/education/is2002.pdf

Halawi, L., \& McCarthy, R. (2006). Which theory applies: An analysis of information systems research. Issues in Information Systems: The Changing Role of IS Education, 7(2), 252-256.

Hardin, M., Joshi, K., \& Li, X. (2002). Business as usual? IS job skills requirements during the Internet era. Proceedings of the 8th Americas Conference on Information Systems, 2143-2150.

Heritage, J. (1984). Garfinkel and ethnomethodology. Cambridge, MA: Polity.

Horgan, R. (2012). History of LinkedIn. Retrieved from http://www.sophisticatededge.com/history-of-linkedin.html

Huang, H., Joshi, K., Kvasny, L., Mahar, J., \& Trauth, E. (2009). Synthesizing IT job skills identified in academic studies, practitioner publications and job ads. SIGMIS-CPR, 121-127.

IT staffing report. (2005). Chief Information Officer. Retrieved from http://www2.cio.com/research/surveyreport.cfm?ID=84

Jackson, S. (2006). Program effectiveness of job readiness training: An analysis and evaluation of selected programs in St. Louis, Missouri. Doctoral dissertation, Capella University, Minneapolis, MN.

Jacobson, C., \& Armstrong, R. (2000). Information systems professionals for the new millennium: What employers want. Journal of Informatics Education Research, 2(1), 41-48.

Kim, Y., Hsu, J., \& Stern, M. (2006). An update on the IS/IT skills gap. Journal of Information Systems Education, 17(4), 395-402.

Kittner, M., \& Papp, R. (2004, February). Tech skills in ten U.S. cities: Comparing job needs in a changing world. Paper presented at the Southern Association for Information Systems 7th annual conference, Savannah, GA.

LaFrance, G. (2010). Bridging the IT skills gap through industry and academic collaboration. Retrieved from http://www.atrion.net/innovation/published/Documents/bridging-the-it-skills-gap-giselle-lafrance.pdf

Laudon, K. (2011). Occupation and career outlook for MIS majors 2012-2018. Retrieved from http://www.uncg.edu/bae/MIS_Outlook_2012-2018.pdf

Leitheiser, L. (1992). MIS skills for the 1990s: A survey of MIS manager perceptions. Journal of Management Information Systems, 9(1), 69-91.

Lenox, T., \& Woratschek, C. (2003). Too many labels, not enough agreement: Defining sub disciplines in computer science-related fields. Information Systems Education Journal, 1(45), 1-18.

McCubbrey, D., \& Scudder, R. (1988). The systems analysts of the 1990's. Proceedings of the ACM SIGCPR Management of Information Systems Personnel Conference, 8-16.

McPherson, B., \& Mensch, S. (2008). Technology majors preferences for business communications. Retrieved from http://www.aabri.com/manuscripts/08044.pdf

Misic, M. (1996). The skills needed by today’s systems analyst. Journal of Systems Management, 47(3), 34-40. Retrieved from http://www.accessmylibrary.com/article-1G1-18421668/skills-needed-today-systems.html

Noll, C., \& Wilkins, M. (2002). Critical skills of IS professionals: A model for curriculum. Retrieved from http://informingscience.org/jite/documents/Vol1/v1n3p143-154.pdf

Outlay, C., \& Krishnan, P. (2010). Skill gaps and careers in IS compliance: Implications for IS degree programs in the U.S. Proceedings of the 2010 Special Interest Group on Management Information System's 48th annual conference on Computer Personnel Research (SIGMIS-CPR), 130-135.

Pitts, M., \& Browne, G. (2004). Stopping behavior of systems analysts during information requirements elicitation. Journal of Management Information Systems, 1(21), 203-226.

Rouibah, K. (2012). Understanding drivers and obstacles toward MIS major and the perspective of an arab country: The case of Kuwait. Retrieved from iacis.org/iis/2012/88_iis_2012_58-71.pdf

Shakirova, D. (2007). Technology for the shaping of college students' and upper-grade students' critical thinking. 
Russian Education Society, 49(9), 42-52.

Shelly, G., \& Rosenblatt, H. (2010). Systems analysis and design (8th ed.). Boston, MA: Course Technology.

Shi, H. (2011). A practical teaching approach to management information system course. Computer Science \& Education (ICCSE), 2011 6th International Conference, 3(5), 631-633. http://dx.doi.org/10.1109/ICCSE.2011.6028718

Shrout, E. (1970). Competencies and training requirements for information systems analysts. Proceedings of the Ninth Annual Computer Research Conference, 75-100.

Stevens-Huffman, L. (2011). Wanted: Problem-solving and communications skills. Retrieved from http://resources.dice.com/2011/12/16/problem-solving-hiring/

Surendra, N., \& Denton, J. (2009). Designing IS curricula for practical relevance: Applying baseball's money-ball theory. Journal of Information Systems Education, 20(1), 77-86.

Swanson, R., \& Holton, E. (2005). Foundations and methods of inquiry. San Francisco, CA: Berrett-Koehler.

Tarafdar, M., \& Gordon, S. (2007). Understanding the influence of information systems competencies on process innovation: A resource-based view. Journal of Strategic Information Systems, 16(4), 353-392.

Todd, P., McKeen, J., \& Gallupe, R. (1995). The evolution of IS job skills: A content analysis of IS job advertisements from 1970 to 1990. MIS Quarterly, 19(1), 1-24.

Trauth, E., Farwell, D., \& Lee, D. (1993). The IS expectation gap: Industry expectations versus academic preparation. MIS Quarterly, 17(3), 293.

Trauth, E., Lee, D., \& Farwell, D. (1995). Critical skills and knowledge requirements of IS professionals: A joint academic/industry investigation. MIS Quarterly, 3(19), 313-332.

Wang, S., \& Wang, H. (2011). Teaching higher order thinking in the introductory MIS course: A model-directed approach. Journal of Education for Business, 86(4), 208-213. http://dx.doi.org/10.1080/08832323.2010.505254

Watson, H., Young, D., Miranda, S., Robichaux, B., \& Seerly, R. (1990). Requisite skills for new. MIS Hires Data Base, 21(2), 20-29.

Wehrs, W. (2002). An assessment of the effectiveness of cooperative learning in introductory information systems. Journal of Information Systems Education, 13(1), 37-49.

Yew, B. K. (2008). A perspective on a management information systems (MIS) program review. Journal of Information Technology Education, 7, 299-314. 